\title{
Aqueous ethanol laminar burning velocity measurements using constant volume bomb methods
}

N. Hinton, R. Stone; Department of Engineering Science, University of Oxford Roger Cracknell, Shell Global Solutions (UK)

Carsten Olm, Institute of Chemistry, Eötvös Loránd University (ELTE), Budapest, Hungary, and Numerical Thermo-Fluid Dynamics, TU Bergakademie Freiberg, Germany

\section{Corresponding author}

\author{
Richard Stone \\ Department of Engineering Science \\ Parks Rd \\ OXFORD OX1 3PJ
}

$+44(0) 1865273139$

\section{richard.stone@eng.ox.ac.uk}

\section{Abstract}

Ethanol is attractive as a renewable fuel for spark ignition engines, and can also be used as an extender in gasoline (up to about $20 \%$ by volume) or as a major component (say above $70 \%$ by volume). There are three reasons for wanting to know the laminar burning velocity of water/ethanol/air mixtures. The first reason is that a significant fraction of the fuel calorific value is required to remove the last 10 per cent or so by volume of water from bio-ethanol, and in some applications it might not be necessary to remove all the water. The second reason is to provide extended data for model validation. The third reason is that in turbocharged engines the knock-free operating range can be extended through water addition so as to improve both output and efficiency. 
during the constant pressure period and b) analyzing the pressure rise data. When the pressure rises the adiabatic core is compressed isentropically, so if a combustion model is used, a single experiment generates a sequence of measurements that include data at high temperatures (up to $600 \mathrm{~K}$ ) and high pressures (up to 12 bar) that are relevant to spark ignition engine combustion. Data from the two methods is shown here to be consistent and in-line with published data for ethanol, and satisfactory comparisons have also been found with predictions from kinetic mechanisms for the ethanol/water/air mixtures. The constant volume combustion vessel also generates data on the Markstein length and the pressure at the onset of cellularity, with both being increased by the presence of water.

The laminar burning velocity has a direct influence on the early flame growth in a spark ignition engine, and unless the ignition timing is adjusted for slow burning mixtures there will be a significant loss of efficiency. Engine data show that even with $40 \%$ water by volume in the ethanol, combustion performance is still acceptable if the ignition timing is advanced.

Keywords: ethanol, aqueous ethanol, laminar burning velocity, Markstein length, cellularity

\section{Introduction}

With environmental concern regarding the emissions of $\mathrm{CO}_{2}$ from the transport sector, liquid biofuels are seen as a way of reducing reliance on fossil fuels whilst maintaining the high energy density provided by liquid fuels. For example, Directive 2009/28/EC of the European Parliament and of the Council of 23 April 2009 [1] requires a "mandatory 10\% minimum target to be achieved by all Member States for the share of biofuels in transport petrol and diesel consumption by 2020". 
Despite acknowledged issues regarding production and the effect of associated indirect land use change, ethanol has received much attention as a potential biofuel, and is already in use globally, either as a neat fuel (E100), or blended with a base gasoline (e.g E85). In some countries, such as Brazil, flex fuel engines, designed to run on any blend of gasoline and ethanol are widespread. E100 cannot easily be used in most countries as the vapour pressure is too low and this leads to difficulties in cold-starts. When gasoline is added to ethanol it increases the vapour pressure significantly because of substantial deviations from Raoult's law. Similarly, when ethanol is added to gasoline it also increases the vapour pressure significantly, and specifications for the vapour pressure of gasoline can limit the amount of ethanol that might be added.

Ethanol has been used extensively in automotive fuels primarily as a fuel extender and antiknock agent in ethanol gasoline blends, and ethanol was considered as an alternative for reducing dependency on oil reserves as early as the 1920s [2]. The advantages of ethanol include: higher octane number (allowing higher compression ratios) and the reduced demand on petroleum fuels. Wang et al. [3] have reported on the benefits of the higher octane rating and the separated these from the benefits associated with the higher enthalpy of evaporation. Wang et al. [3] report on tests that compare ethanol blends with hydrocarbon fuels that have matched Research Octane Number (RON) and Motor Octane Number (MON) values. At the knock-limited engine loads the ethanol fuels with a higher ethanol content allowed higher engine thermal efficiency, this is because the ignition timing need not be retarded and there was less fuel enrichment for limiting the exhaust gas temperature. This was because the higher enthalpy of vaporisation of ethanol increased the charge cooling, thereby reducing the engine knock tendency because the unburned gas temperature was lowered. Pure ethanol fuel (E100) has also been studied, for example Brewster [4] demonstrated a higher output and brake efficiency. 
To minimise the impacts of ethanol production, processing routes should be examined to determine where savings in terms of energy production can be made. Some of the biggest savings are achieved by reducing the energy required for the removal of water from the bio-produced ethanol since ethanol forms an azeotropic mixture with water $(95.6 \%$ by weight ethanol or $97 \%$ by volume). Fermentation will typically produce an ethanol concentration of around $12 \%$ by volume, meaning that to produce neat ethanol, extensive distillation is required. Data from Martinez-Frias et al. [5] shows that the distillation energy requirement increase almost linearly to become $10 \%$ of the Lower Heating Value (LHV) of ethanol to produce $80 \%$ by volume ethanol. There is then an asymptotic increase in energy requirements as the azeotrope is approached, so that $90 \%$ by volume ethanol requires $23 \%$ of the LHV of ethanol, with a further $14 \%$ of the energy required for dehydration beyond the azeotrope. These results are summarised in Table 1 that also defines the corresponding mass and molar compositions.

Table 1 The energy requirements for separating ethanol from water expressed as a percentage of the Lower Heating Value (LHV); data from (5)

\begin{tabular}{|c|c|c|c|}
\hline \multicolumn{3}{|c|}{ Ethanol Concentration } & \multirow{2}{*}{$\begin{array}{r}\% \text { of LHV } \\
\text { for Separation }\end{array}$} \\
\hline$\%$ vol & $\%$ mass & $\% \mathrm{~mol}$ & \\
\hline 12 & 9.7 & 4.0 & 0 \\
\hline 80 & 75.9 & 55.3 & 10 \\
\hline 90 & 87.7 & 73.5 & 23 \\
\hline 96.5 & 95.6 & 89.5 & Azeotrope \\
\hline 100 & 100.0 & 100.0 & 37 \\
\hline
\end{tabular}

It is also important to recognise that the method of manufacturing ethanol can have a profound impact on the "Well to Tank" Greenhouse Gas (GHG) emissions. In general, advanced ethanol from residual feedstock material (e.g. waste wood, straw, bagasse from sugar cane) will give a better GHG reduction than from farmed materials. See Table 2 for selected results from the 2014 JEC/EUCAR/CONCAWE European well to wheels study [6]. 
Clearly the source of any external energy required for the process will strongly influence the GHG

emissions. However, the way that co-products are accounted for can also have a profound impact on the GHG impact of ethanol production. Common examples of co-products are slops from sugar

Table 2 Well-to-tank (WTT) Greenhouse Gas (GHG) emissions for ethanol produced from different sources, compared with conventional gasoline; data from [6]

\begin{tabular}{|c|c|c|c|c|}
\hline & & $\begin{array}{l}\text { WTT GHG } \\
\text { emitted } \\
\text { (g CO2 eq./ } \\
\text { MJ final } \\
\text { fuel) } \\
\text { RANGE }\end{array}$ & 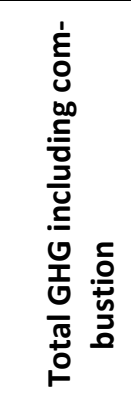 & $\begin{array}{c}\% \\
\text { GHG saving } \\
\text { relative to } \\
\text { gasoline }\end{array}$ \\
\hline Conventional Gasoline & & $12.2-15.3$ & 87.1 & \\
\hline $\begin{array}{l}\text { Ethanol } \\
\text { (1 }{ }^{\text {st }} \text { Generation) }\end{array}$ & $\begin{array}{l}\text { Sugar beet, pulp to AF, slops not } \\
\text { used } \\
\text { Sugar beet, pulp to AF, slops to } \\
\text { biogas } \\
\text { Corn US, DDGS as AF } \\
\text { Wheat conv NG boiler, DDGS as } \\
\text { AF } \\
\text { Sugar cane (Brazil) }\end{array}$ & $\begin{array}{l}37.4-42.3 \\
24.4-28.9 \\
66.6-70.5 \\
65.4-71.8 \\
22.7-26.9\end{array}$ & \begin{tabular}{r|}
40.3 \\
27.2 \\
68.9 \\
69.4 \\
24.8 \\
\end{tabular} & $\begin{array}{l}54 \\
69 \\
21 \\
20 \\
72\end{array}$ \\
\hline $\begin{array}{l}\text { Ethanol } \\
\text { (2 } 2^{\text {nd }} \text { Generation) }\end{array}$ & $\begin{array}{l}\text { Waste Wood } \\
\text { Wheat Straw }\end{array}$ & $\begin{array}{l}19.3-19.6 \\
9.1-9.2\end{array}$ & $\begin{array}{l}19.5 \\
9.2\end{array}$ & $\begin{array}{l}78 \\
89\end{array}$ \\
\hline
\end{tabular}

An additional complication is accounting for Land Use Change (LUC) to reflect the fact that the Solid Organic Content (SOC) can either decrease or increase, depending on the crop. If land is converted from cropland-pasture to maize, the SOC will decrease, and carbon will be released to the atmosphere. However, conversion of this same type of land to miscanthus or switchgrass production is thought to sequester carbon $[7,8]$. 
In many cases, a crop going into production of biofuels comes from land which was already

producing that crop, and there is no additional carbon sequestration associated with the change of use of that crop, that is no Direct LUC. However, diverting land from food to biofuel production potentially results in food crops being grown elsewhere, potentially resulting in carbon being released form an Indirect LUC. This is however extremely difficult to account for [8].

A study by Brewster et al. [9] investigated the effect of water content on the performance of a direct injection multi-cylinder turbocharged engine developed to run on E100, and found that increasing the water content resulted in reduced output and efficiency, but this can be attributed to the ignition timing not being re-optimised. The increased water content results in lower combustion temperatures and hence lower $\mathrm{NO}_{\mathrm{x}}$, as well as supressing knock and pre-ignition, presenting opportunity to extend the engine operating regime. Wyman and Hinman [10] report fewer volatile organic compounds (VOCs) emissions and fewer smog producing compounds. Costa and Sodré [11] compared the performance of a 1.0 litre flex-fuel engine when operated on a gasolineanhydrous ethanol blend ( $22 \%$ by volume) and a hydrous ethanol fuel ( $6.8 \%$ water by mass), to provide a comparison with a typical ethanol blend. This study showed that it is possible to achieve a comparable power output, although advanced ignition timing is required to enable this. A further application for hydrous ethanol is in Homogeneous Charge Compression Ignition (HCCI) engines. Whilst fuel with high concentrations of water can be problematic in SI or diesel engines, HCCI is better suited to hydrous ethanol, provided the fuel can be fully vaporised before combustion. Mack et al. [12] successfully ran a HCCI engine on hydrous ethanol mixtures with up to $60 \%$ water. 
Hydrous ethanol also provides opportunities for steam reforming. Shimada and Ishikawa [13] tested such a system, and reported thermal efficiencies of 1.18 times that of a conventional spark ignition engine.

Whilst hydrous ethanol clearly presents opportunities for improved energy efficiency, blending with gasoline can be problematic due to the immiscibility of water and gasoline, which can lead to phase separation within the fuel blend. Ormandy and Craven [2 ] report on the ethanol/water/hydrocarbon phase equilibria for a number of hydocarbons, including benzene, di-methyl benzene and several alkanes (C5 to $\mathrm{C} 7)$ and some gasolines. They show that the aromatics are more tolerant of water than the alkanes and that as the number of carbon atoms increases, then the tolerance reduces. They also report how the tolerance reduces with temperature. There have been many more recent reports on the phase equilibria of ethanol blends. French and Malone [14] consider the impact of ethanol on the vapour pressure and distillation characteristics of ethanol gasoline mixtures, and present ternary equilibrium diagrams for water and ethanol mixtures with both trimethyl pentane and toluene (methyl benzene). They include tie-lines (that can be used to identify the composition of the two phases (one being mostly ethanol and water with traces of hydrocarbons, and the other being ethanol and hydrocarbons with traces of water).

\section{Measurement of burning velocity}

A combustion bomb with a diameter of $160 \mathrm{~mm}$ was used. This has quartz windows (with a viewing diameter of $40 \mathrm{~mm}$ ) to allow imaging of the initial stages of flame propagation using a schlieren system with a high speed camera. A pressure transducer is used to measure the pressure rise in the vessel during combustion. The premixed mixture of fuel and air is ignited using a pair of electrodes forming a spark gap at the centre of the vessel. Burning velocity measurements have been made from two methods over a range of initial temperatures $(380$ and $450 \mathrm{~K})$, initial pressures $(0.5,1,2$ 
and 4 bar) and equivalence ratios in the range of 0.7 to 1.4 , for hydrous ethanol mixtures containing up to $40 \%$ water by volume.

The two methods have been explained recently elsewhere [15], but a summary is provided in Figure 1.
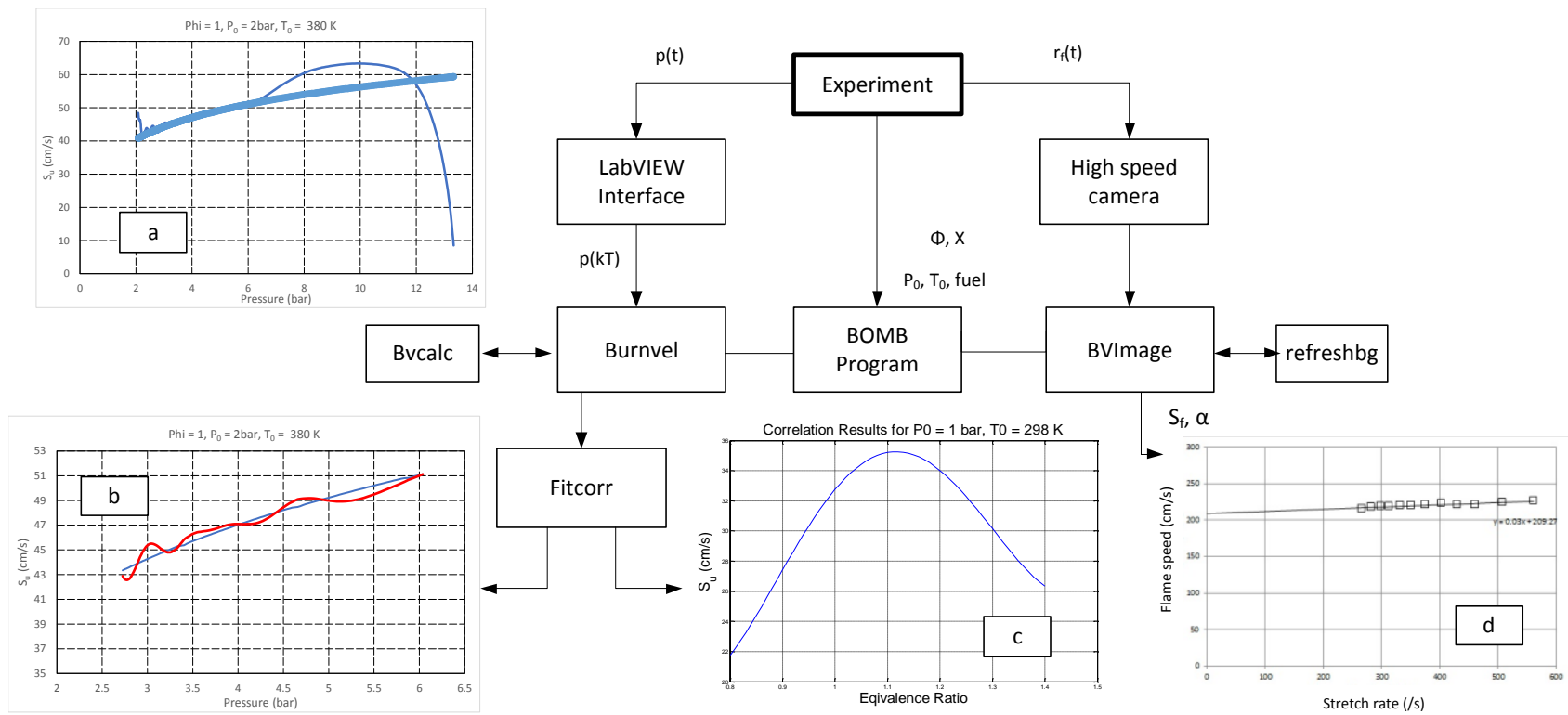

Figure 1 - Schematic diagram of data analysis procedures for both constant pressure and pressure rise techniques using stoichiometric data with an initial temperature of $380 \mathrm{~K}$ and a pressure of 2 bar as an example. The insets that show (a) burning velocity calculated as the pressure rises (using thermodynamic data from the multi-zone BOMB program), (b) fit of the global correlation (see Eq. 1) to the data selected from a single experiment, (c) a sample plot from the resulting correlation and (d) extrapolation of flame speed to zero stretch from the flame imaging (using BVImage and thermodynamic data from the BOMB program).

As the initial stages of combustion take place at conditions of constant pressure, the images obtained (such as those shown in Figure 2) allow for a constant pressure analysis of flame speed. Due to the small radius of curvature of the flame at initial conditions, the flames are highly stretched, so a linear 
extrapolation of the flame speed to conditions of zero stretch is used (Figure 2d), as performed in many existing studies such as that of Bradley et al. [16]. The constant pressure imaging also allows determination of Markstein lengths, which describe the response of the flame to stretch.
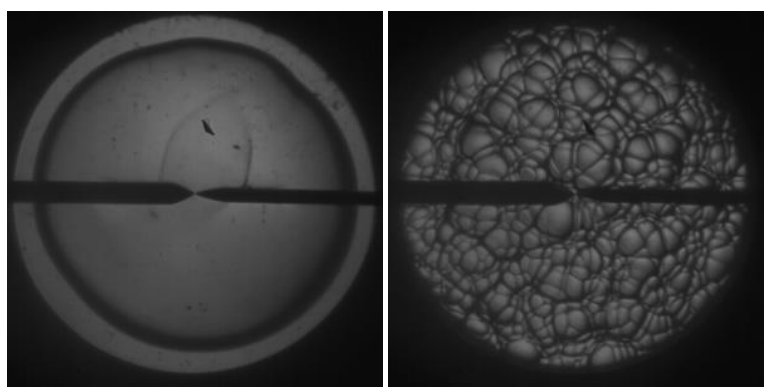

Figure 2 - Schlieren images of the flame front during initial stages of combustion and later, once cellularity has occurred.

Once the flame has passed beyond the field of view, combustion can no longer be considered to be taking place at constant pressure, so a constant volume combustion analysis is performed. By combining the pressure record with a model for constant volume combustion it is possible to determine the burning velocity following the method of Lewis and von Elbe [17]. Because of the isentropic compression of the unburned gas, this method allows burning velocity to be measured for a wide range of temperature and pressure of the unburned gas from a single experiment. However, the range of data which can be included in the analysis is limited by the onset of cellularity (as shown in Figure 2, and the marked increase in burning velocity seen in Figure 1a). Cellularity violates the condition of a smooth spherical flame front needed for the analysis. Data accumulated from a number of experiments over a range of initial temperatures, pressures volume fractions of water and equivalence ratios is combined and fitted to a 14 term correlation:

$$
S_{u}=\left[S_{u, 0}+S_{u, 1}(\phi-1)+S_{u, 2}(\phi-1)^{2}+S_{u, 3}(\phi-1)^{3}+S_{u, 4}(\phi-1)^{4}\right]
$$

where:

$$
\times T^{\alpha} P^{\beta} \times\left(1-\mu_{1} V F_{w}{ }^{\mu}\right)
$$




$$
\begin{gathered}
\beta=\beta_{0}+(\phi-1) \beta_{1}+(\phi-1)^{2} \beta_{2} \\
\mu=\mu_{2}+(\phi-1) \mu_{3}
\end{gathered}
$$

and $V F_{\mathrm{w}}$ is the volume fraction of water.

A quadratic dependence of the temperature and pressure exponent upon equivalence ratio has been used, as in the work of Konnov et al. [18].

The sources of error can be separated into three parts: type 1) those associated with mixture preparation, type 2) combustion measurements and type 3) data analysis; these have all been analysed recently [15]. In summary, the likely error range in mixture preparation is +0.5 to $-0.4 \%$. With flame speed measurements, the only significant error is that associated with extrapolation to zero stretch, and this is estimated to be about $3 \%$. For the pressure rise data there might be errors of order $1 \%$ in the computed velocities, but additional errors might be introduced by the form of the correlation being an intrinsically poor fit to the data, and this cannot be quantified. It will be seen later that there is essentially good agreement between the individual measurements of the laminar burning velocity from the flame imaging with the correlated values derived from the pressure data so this supports the estimates presented here for the type 2 and type 3 errors.

\section{Results}

\subsection{Laminar Burning Velocity}

Over 150 experiments were conducted, yielding over 18000 data points that were fitted to the correlation. The correlation coefficients are presented in Table 3, and the range of the experimental data points is summarised in Table 3. The range of data validity is further restricted by the onset of cellularity (section 3.3) as will be seen later in Figures 9 and 10. 


\begin{tabular}{|l|l|l|l|l|l|l|}
\hline $\mathrm{S}_{\mathrm{u}, 0}$ & $\mathrm{~S}_{\mathrm{u}, 1}$ & $\mathrm{~S}_{\mathrm{u}, 2}$ & $\mathrm{~S}_{\mathrm{u}, 3}$ & $\mathrm{~S}_{\mathrm{u}, 4}$ & $\alpha_{0}$ & $\alpha_{1}$ \\
\hline 35.615 & 21.159 & -130.38 & -38.952 & 79.839 & 1.9195 & -0.2463 \\
\hline \multicolumn{7}{|l|}{} \\
\hline$\alpha_{2}$ & $\beta_{0}$ & $\beta_{1}$ & $\beta_{2}$ & $\mu_{0}$ & $\mu_{1}$ & $\mu_{2}$ \\
\hline 2.3624 & -0.2596 & 0.2100 & -0.3083 & 1.4380 & 1.4111 & 0.2006 \\
\hline
\end{tabular}

Table 4

Minimum and maximum conditions in the hydrous ethanol data sets

231

\begin{tabular}{|c|c|c|c|c|c|c|c|}
\hline \multirow[b]{2}{*}{ Property } & \multirow[b]{2}{*}{ Unit } & \multicolumn{2}{|c|}{ W0 } & \multicolumn{2}{|c|}{ W20 } & \multicolumn{2}{|c|}{ W40 } \\
\hline & & Min & Max & Min & Max & Min & Max \\
\hline$T_{0}$ & $\mathrm{~K}$ & 380 & 450 & 380 & 450 & 380 & 450 \\
\hline$P_{0}$ & bar & 0.5 & 4.0 & 1.0 & 4.0 & 1.0 & 4.0 \\
\hline$\Phi$ & & 0.70 & 1.41 & 0.62 & 1.39 & 0.70 & 1.59 \\
\hline$P_{\mathrm{u}}$ & bar & 0.656 & 16.9 & 1.28 & 15.4 & 1.36 & 14.8 \\
\hline$T_{\mathrm{u}}$ & K & 393 & 633 & 394 & 633 & 393 & 624 \\
\hline$S_{\mathrm{u}}$ & $\mathrm{cm} \mathrm{s}^{-1}$ & 21.9 & 106 & 19.9 & 92.1 & 12.3 & 68.3 \\
\hline$S_{\mathrm{f}}$ & $\mathrm{cm} \mathrm{s}^{-1}$ & 40.5 & 351 & 32.6 & 272 & 25.3 & 224 \\
\hline$A$ & $\mathrm{~s}^{-1}$ & 10.8 & 146 & 8.81 & 105 & 7.20 & 78.8 \\
\hline$r_{\mathrm{b}}$ & $\mathrm{mm}$ & 39.4 & 77.4 & 33.7 & 77.8 & 39.2 & 77.2 \\
\hline$T$ & $\mathrm{~ms}$ & 14.5 & 92.3 & 19.0 & 130 & 25.4 & 159 \\
\hline
\end{tabular}

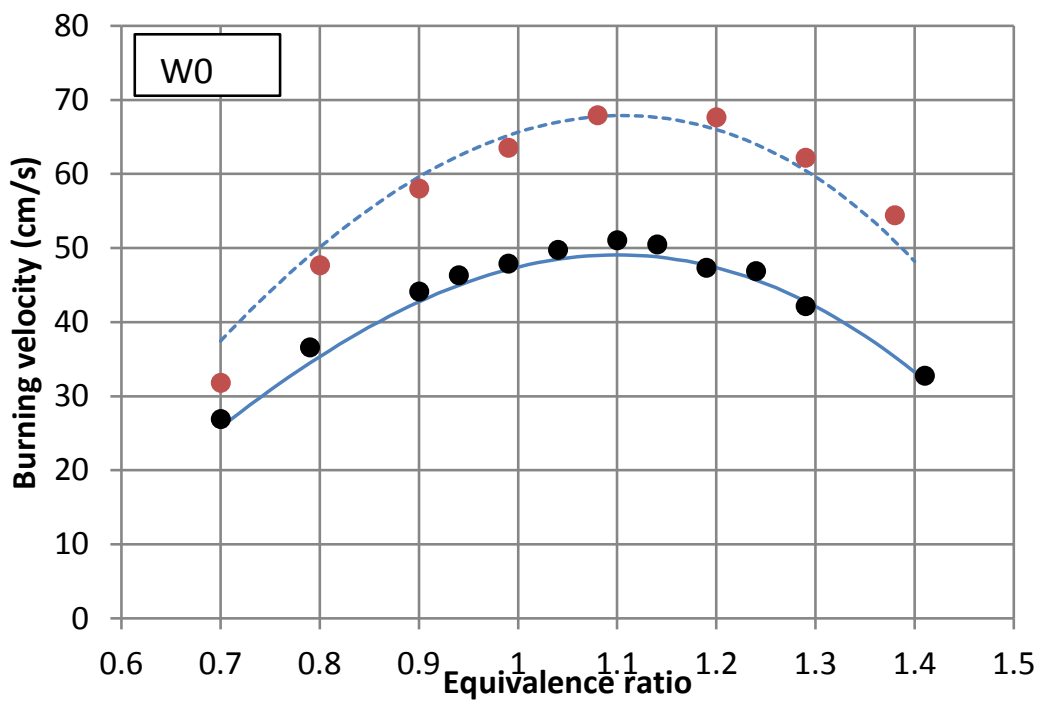



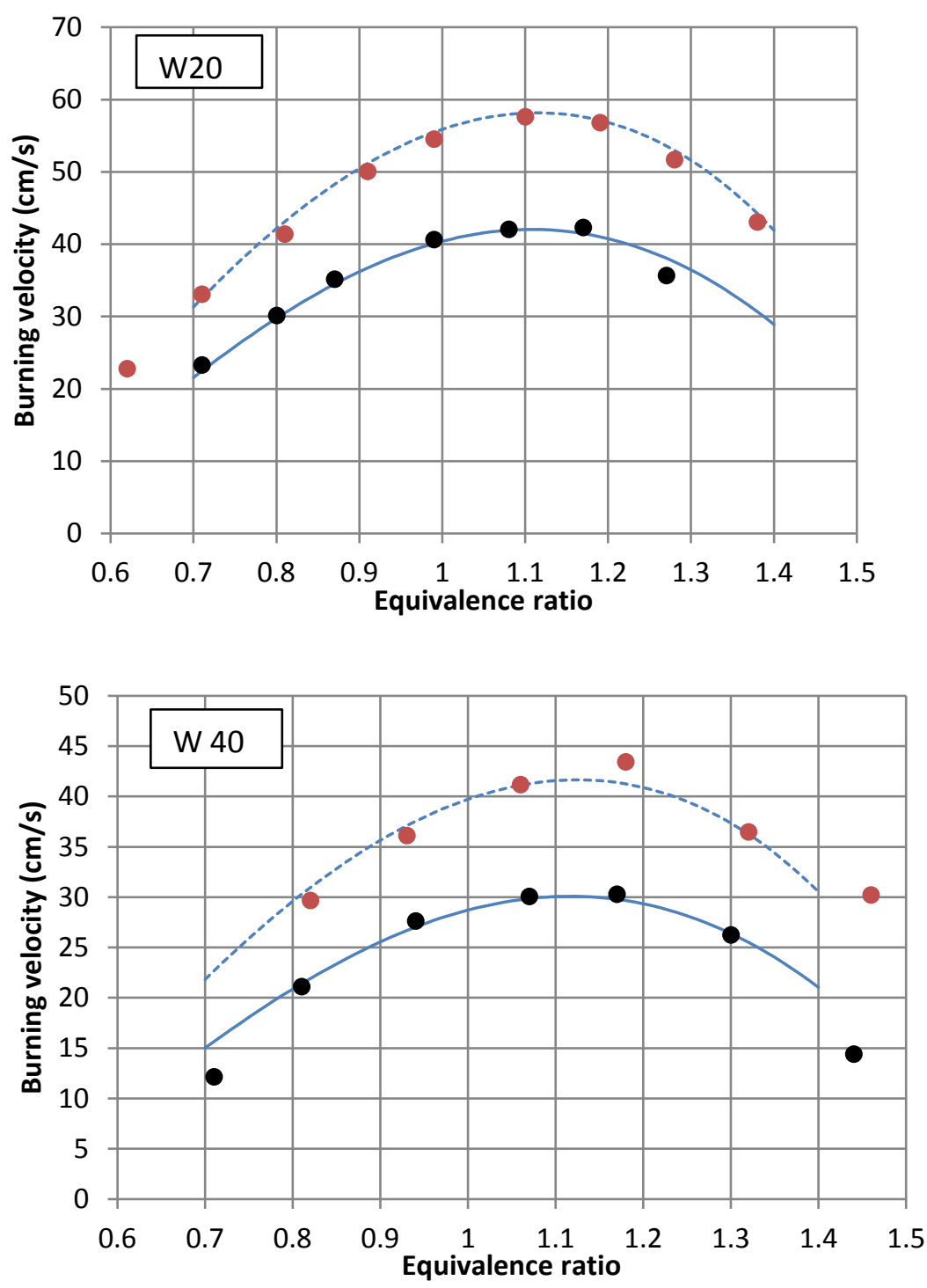

Figure 3 - Laminar burning velocity data for ethanol/water air mixtures at 2 bar with temperatures of $380 \mathrm{~K}$ (solid line) and $450 \mathrm{~K}$ (broken line); W20 and W40 are ethanol-water blends containing $20 \% \mathrm{v} / \mathrm{v}$ and $40 \% \mathrm{v} / \mathrm{v}$ of water. The data points are from flame front imaging and the curves are from the correlation, as defined by Equation 1 using the coefficients listed in Table 3. Results for the laminar burning velocity at 2 bar with temperatures of $380 \mathrm{~K}$ and $450 \mathrm{~K}$ are shown in

Figure 3. The W20 and W40 are ethanol-water blends containing $20 \% \mathrm{v} / \mathrm{v}$ and $40 \% \mathrm{v} / \mathrm{v}$ of water.

The data points are from individual experiments that used flame front imaging during the constant pressure period of combustion, and have been extrapolated back to their zero stretch values (see Figure 1d). In contrast the curves are from the correlation (they are not fits to these data points), with the data being derived from the pressure rise measurements using the correlation defined by equation 1 with the coefficients listed in Table 3. As expected, raising the temperature increases the 
laminar burning velocity while increasing the water content reduces the laminar burning velocity; the maximum values occur just rich of stoichiometric.

Comparisons can be made with published data for ethanol air mixtures, but there is very little data for aqueous ethanol air mixtures. Figure 4 shows literature values for ethanol-air (W0) mixtures at 1 bar, $358 \mathrm{~K}$, along with the current correlation which has had to be extrapolated below the region of validity. The correlation has better agreement weak of stoichiometric; for rich mixtures fewer data points are available for fitting in the correlation because of the earlier onset of cellularity (see section 3.3). The results of Gülder [19] are acknowledged to be slightly higher at the peak, and exhibit a steeper drop-off in the rich region. The results of Bradley et al. [20], Konnov et al. [18] and Liao [21] are mostly in better agreement with the current results.

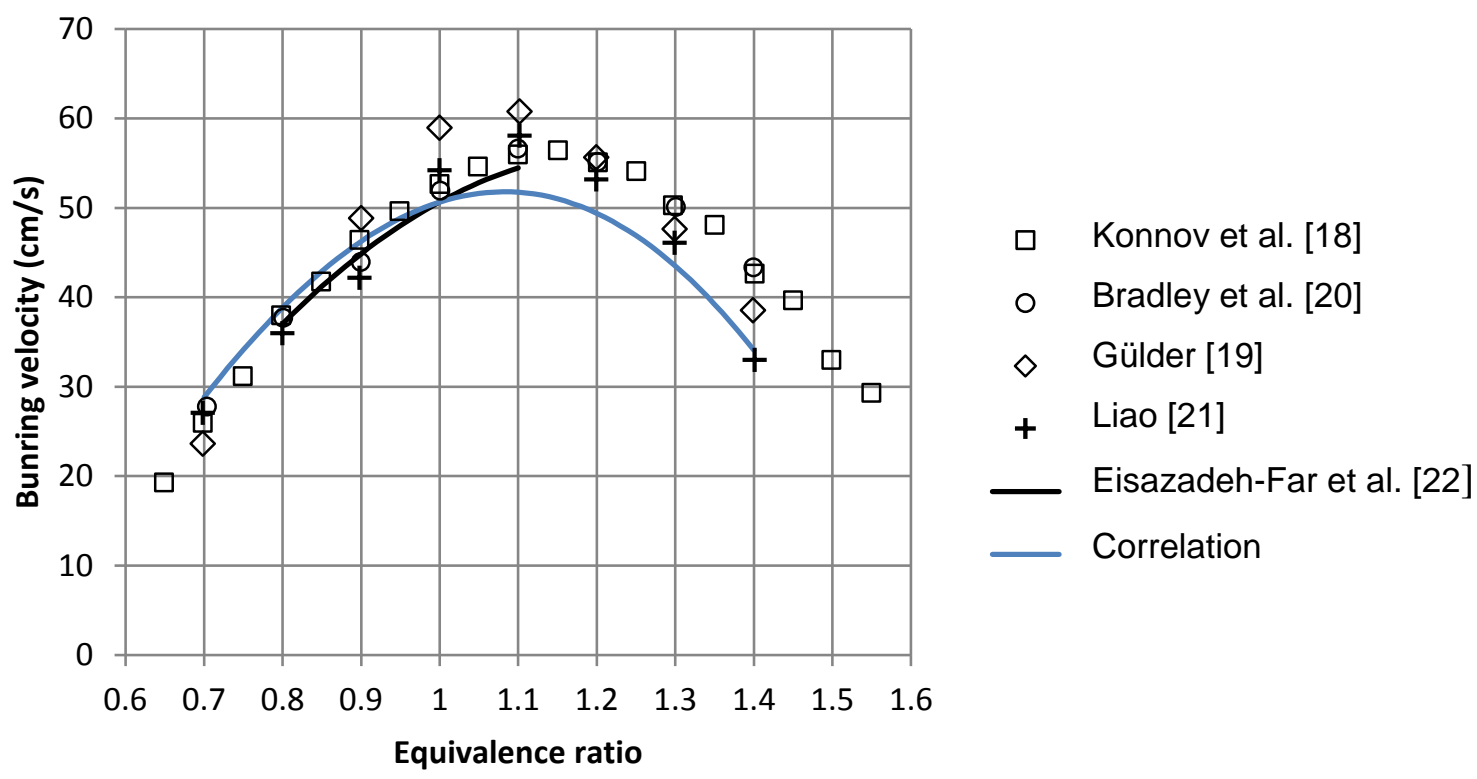

Bradley et al [20] also published ethanol/air data for higher temperatures and pressures and these

Figure 4 - Comparisons of the current correlation (which has had to be extrapolated downwards) with published data for ethanol-air (W0) mixtures at 1 bar, $358 \mathrm{~K}$.

data have been used for a comparison with the current correlation in Figures 5 and 6. 


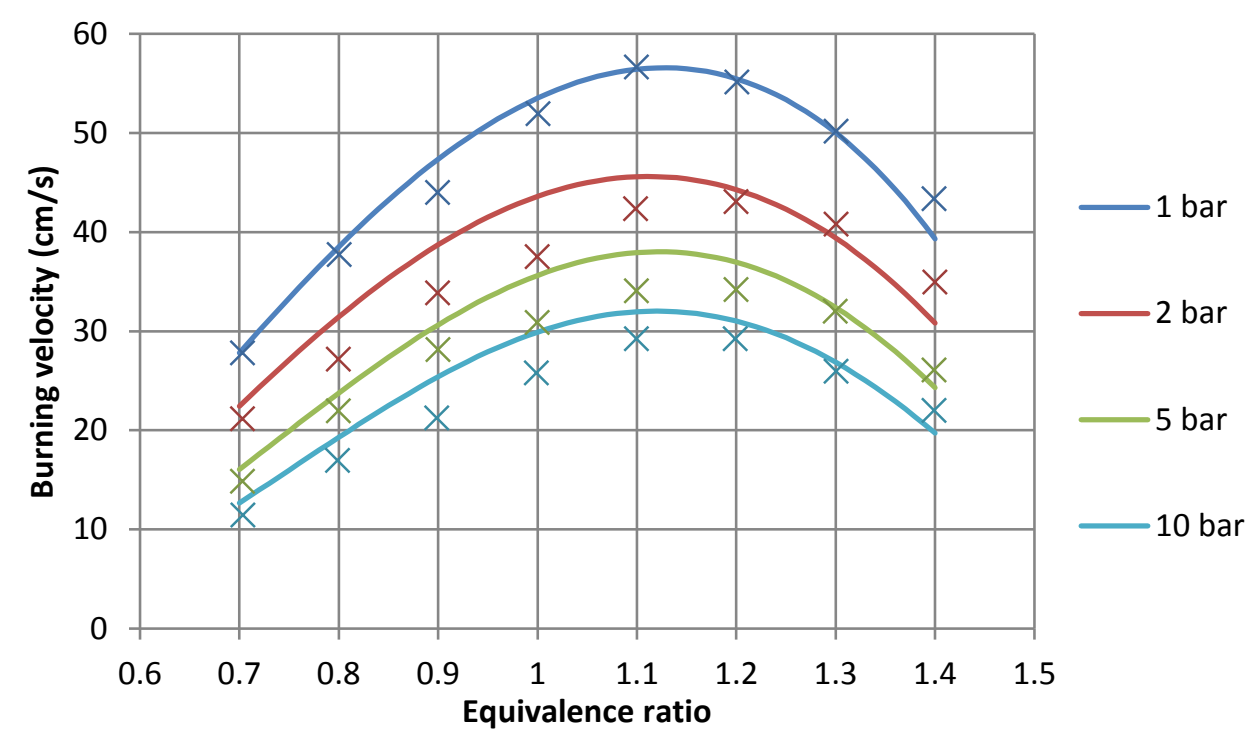

Figure 5 - Burning velocity of ethanol-air mixtures at $358 \mathrm{~K}$ and varying pressure. Crosses are results from Bradley et al. [20]; solid lines represent the current correlation.

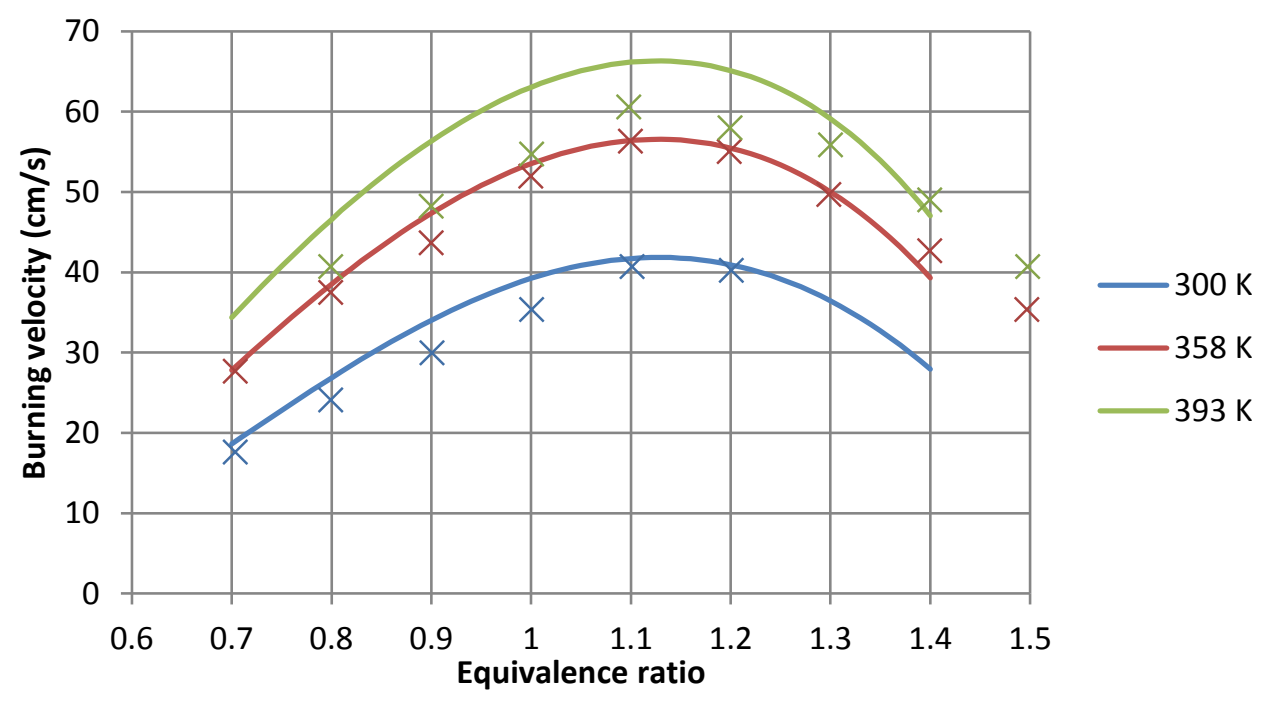

Figure 6 - Burning velocity of ethanol-air mixtures at 1 bar and varying temperature. Crosses are results from Bradley et al. [20]; solid lines represent the current correlation.

Whilst the agreement in Figure 5 is good at lower pressures, at higher pressures the correlation gives higher results, except for rich mixtures. This is due to the fact that the pressure exponent determined empirically from the experimental data of Bradley et al. [20] is of larger magnitude than that determined here and used in the present correlation. Figure 6 compares results at 1 bar with varying 
temperature. Agreement between the correlation and the data is good at $300 \mathrm{~K}$ and $358 \mathrm{~K}$, but for $393 \mathrm{~K}$ the correlation gives higher burning velocities than the results of Bradley et al. [20]. Given the relative burning velocities at the three temperatures, it seems plausible that the $393 \mathrm{~K}$ data presented by Bradley et al. are unrealistically low.

Limited data exists for the burning velocity blends of ethanol and water. Zhang et al. [23] tested mixtures of hydrous ethanol (75\% ethanol by volume) with hydrogen as part of a study into reformer gas using flame front imaging in a cylindrical constant volume vessel. Their results include hydrous ethanol-air mixtures at 1 bar, $383 \mathrm{~K}$, but the correlation developed here gives up to $20 \%$ lower values of burning velocity than the experimental data of Zhang et al. at stoichiometric and rich conditions. Gülder [19] also presents results for hydrous ethanol-air mixtures at 1 bar and $400 \mathrm{~K}$, but gives significantly higher burning velocities than obtained from the correlation, but this is also true for W0, suggesting the data is erroneous, given the agreement between the current correlation and other ethanol-air results at similar conditions.

Comparisons can also be made with numerical predictions and Figure 7 provides chemical kinetic simulations using the mechanisms of Saxena and Williams [24], Leplat et al. [25] and Olm et al. [26] (the ELTE-EtOH-2016 mechanism). Simulations were carried out using CHEMKIN-II PREMIX [27]. The mixture-averaged diffusion model was used and thermal diffusion was accounted for during the simulations. The computational grid in these calculations was set to contain at least 600 points. The GRAD and CURV settings in PREMIX were constrained to be less than 0.1 and were typically around $0.02-0.03$.

It is clear that the three mechanisms used give differing results, and that the Leplat et al. and the ELTE-EtOH-2016 mechanism gives better agreement with the experimental data. The measured burning velocities are higher on the rich side, and this is also the region for the correlation in which there was less data because of the onset of cellularity. 

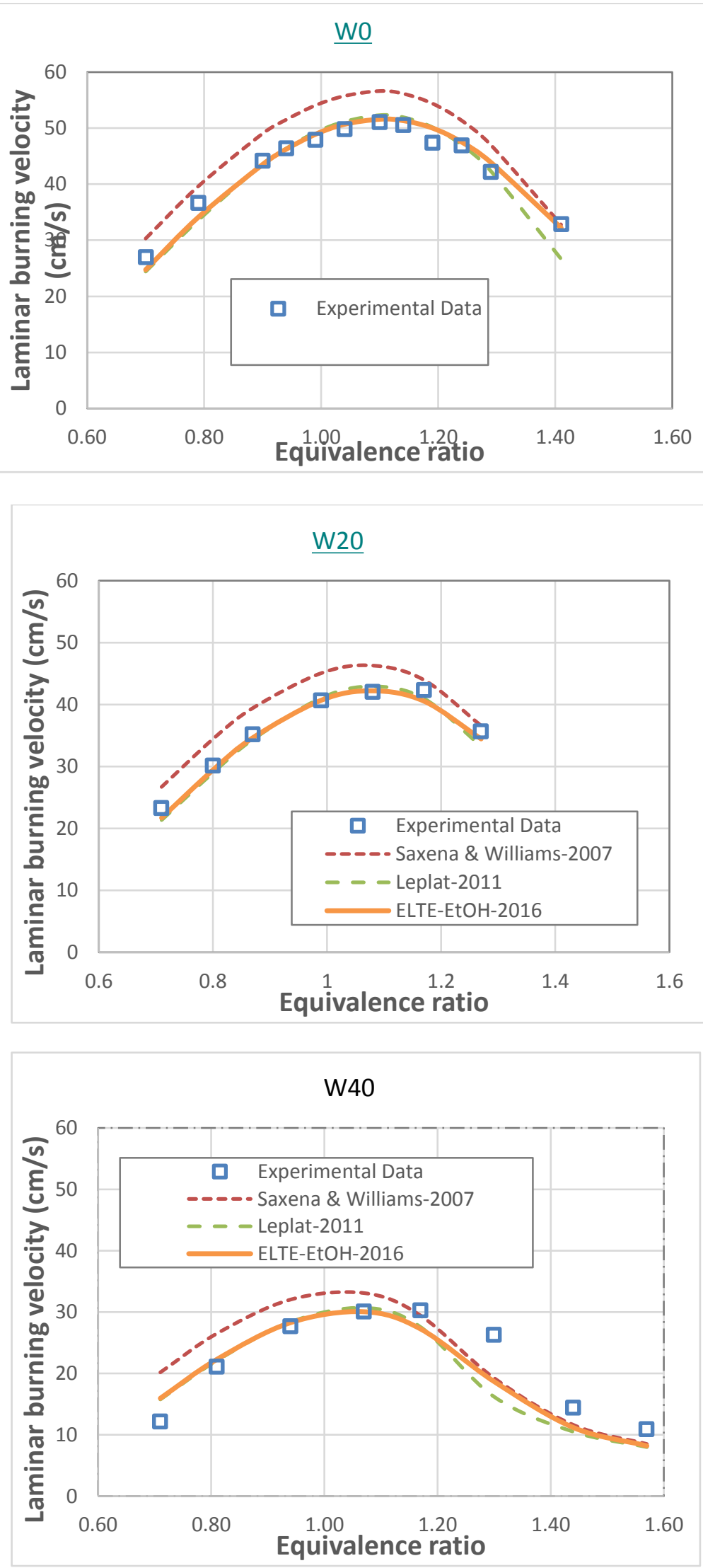

Figure 7 - Experimental results derived from schlieren images of the constant pressure phase for hydrous ethanol at 2 bar, $380 \mathrm{~K}$ compared with the mechanisms of Saxena and Williams [24], Leplat et al. [25] and the ELTE-EtOH-2016 [26]. 


\subsection{Markstein Length}

The Markstein length is derived from the gradient of the plot of flame speed against stretch rate (Figure 1d). Some data for burned gas Markstein lengths $\left(L_{\mathrm{b}}\right)$ for ethanol/air combustion are available in the literature and these show a much stronger dependence on the stoichiometry than either the pressure or temperature. Bradley et al. [20] presents results for ethanol-air mixtures obtained using a spherical vessel with radius of $190 \mathrm{~mm}$ and windows with a radius of $75 \mathrm{~mm}$, with images taken at a frame rate of $2000 \mathrm{fps}$, and a linear extrapolation of flame speed to zero stretch. Tests were performed up to 14 bar when the stability of the flame and maximum combustion pressure allowed, and appear to be the only data for Markstein lengths of ethanol at elevated pressures.

Varea et al. [28] used a novel PIV technique to determine $L_{\mathrm{b}}$ although only at the single condition of 1 bar and $373 \mathrm{~K}$. Broustail et al. [29] also present values of $L_{\mathrm{b}}$ for ethanol from measurements made in a cylindrical vessel, but again only at a single condition of 1 bar and $393 \mathrm{~K}$, using a non-linear extrapolation to zero stretch.

A comparison of the current results at both $380 \mathrm{~K}$ and $450 \mathrm{~K}$ with those reported by the above workers is given in Figure 8. In general the values obtained here are lower than reported elsewhere. Noting that the results of Varea et al. [26] and Broustail et al. [27] are for conditions of 1 bar, we would expect that the higher pressure analysed here would result in a lower Markstein length. The results for $450 \mathrm{~K}$ are very close to those of Bradley et al. [19] which are also for 2 bar. Existing investigations of Markstein lengths do not indicate any consistent trends for temperature dependence. Measurements of Markstein length are subject to considerable amounts of scatter. At higher pressures, Bradley et al. [20] report Markstein lengths for 5 bar, which compare well to the results obtained in the current work at 4 bar for both temperatures tested. 


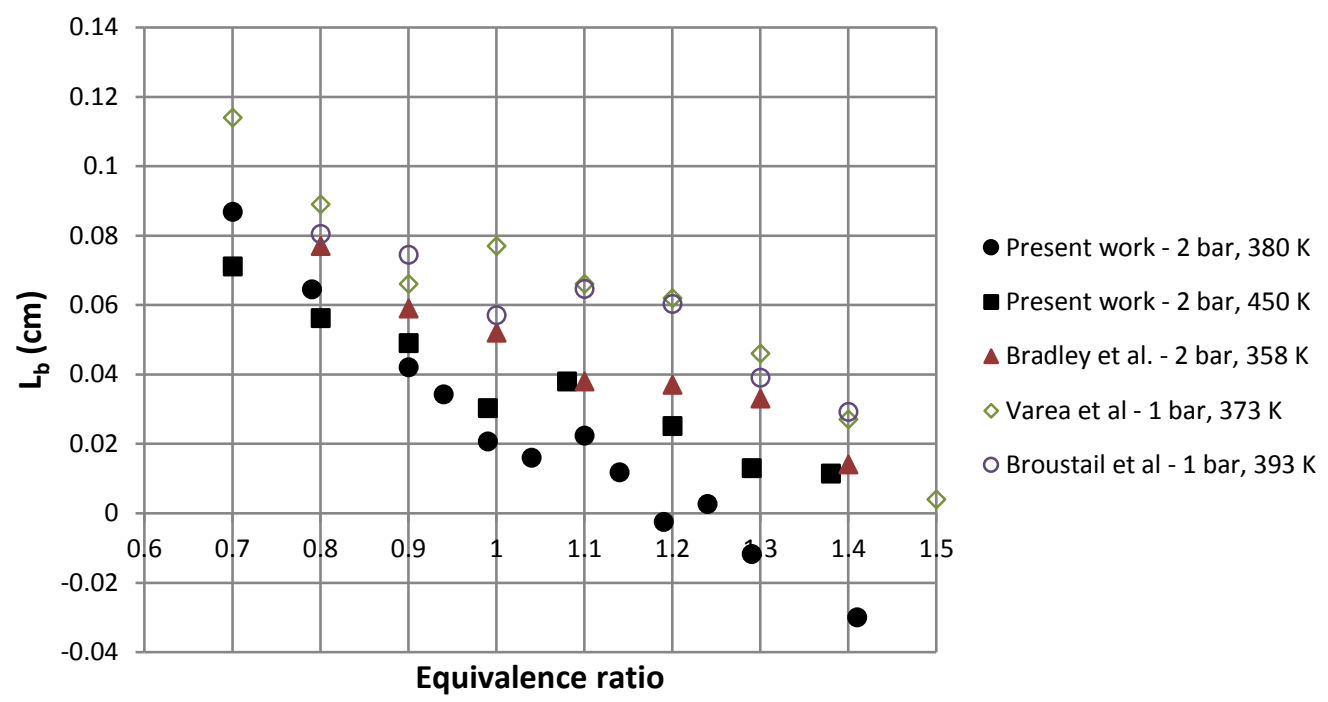

337 Figure 8 - Burned gas Markstein lengths for ethanol-air mixtures obtained in the present work compared with literature values.

The burned gas Markstein lengths can be estimated using the following equations:

Pure ethanol (W0) $\quad L_{\mathrm{b}, 0}=0.03-1.0(\varphi-1) \quad(\mathrm{cm})$

$20 \%$ water $(\mathrm{W} 20) \quad L_{\mathrm{b}, 20}=0.04-1.0(\varphi-1) \quad(\mathrm{cm})$ 


\subsection{Onset of Cellularity}

The onset of cellularity is highly dependent on the stoichiometry and pressure, with only a weak dependence on temperature - so the data presented here in Figure 9 are for both temperatures as a single series. The data collapses onto a single line, apart from the rich of stoichiometric data with the initial pressure of 4 bar, and this is because the 'critical' pressure for the onset of cellularity is below 4 bar. For these high initial pressures the onset of cellularity can be delayed by the high stretch rate which will be greatest for mixtures just rich of stoichiometric.

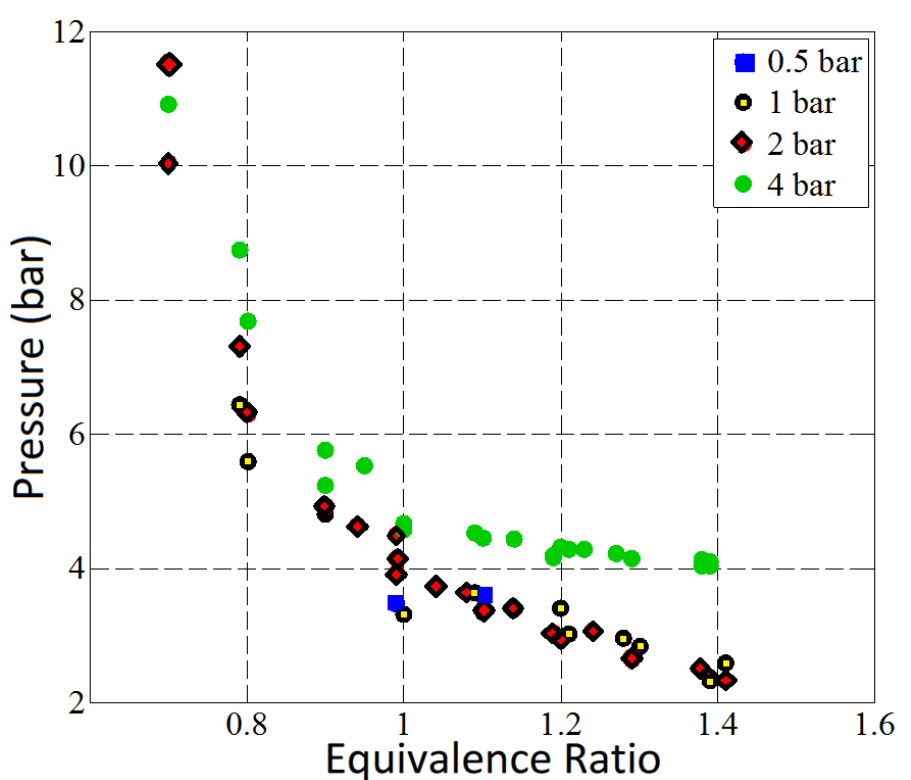

Figure 9 - Pressure at onset of cellularity for ethanol/air mixtures with varying initial pressure and temperatures of 380 and $450 \mathrm{~K}$

The effect of increased water content upon the pressure at onset of cellularity is shown in Figure 10 for experiments with $T_{0}=450 \mathrm{~K}$ and $P_{0}=2 \mathrm{bar}$, where it is seen that the increase in water content in the hydrous ethanol leads to a more delayed onset of cellularity. 


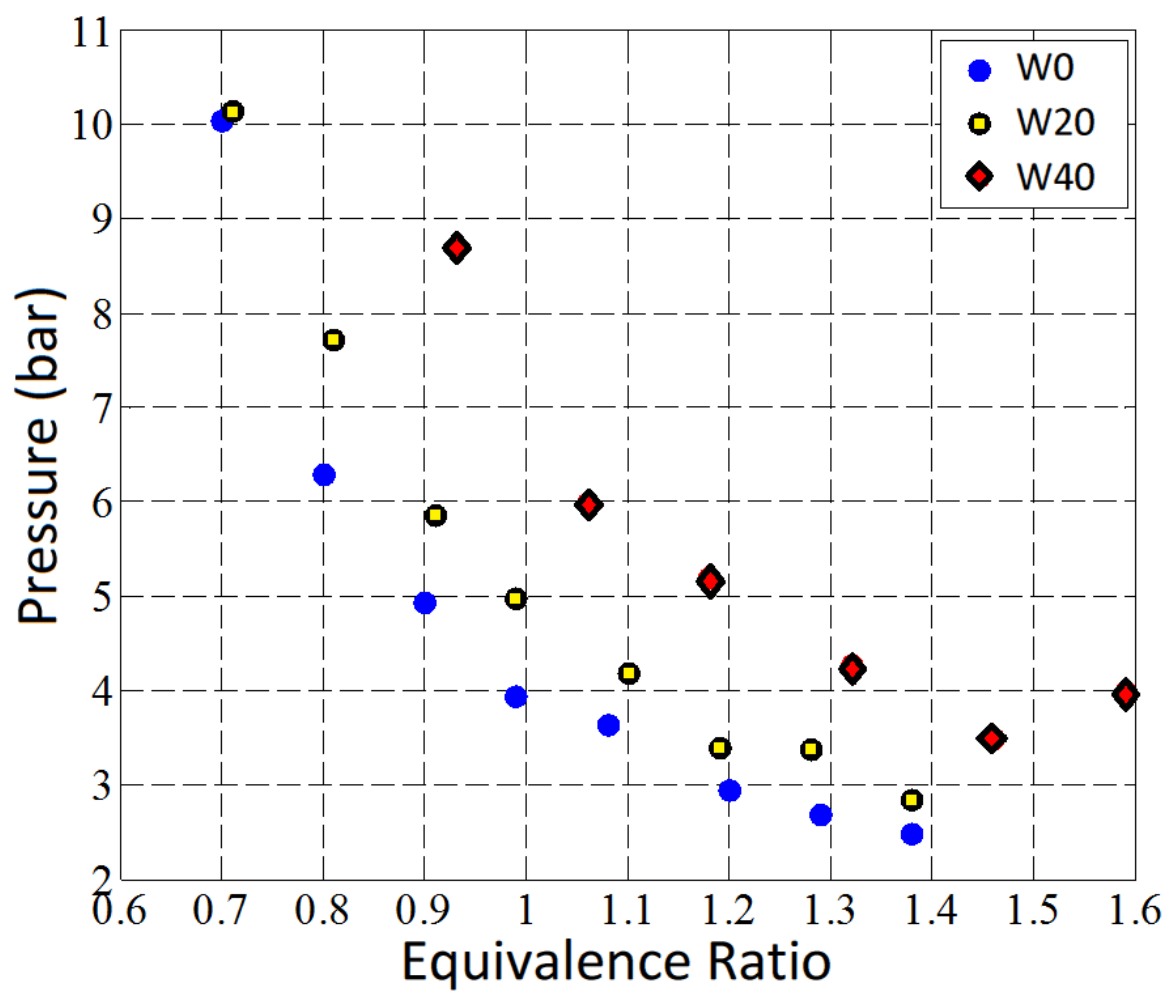

Figure 10 - Onset of cellularity for hydrous ethanol with varying water fraction for experiments with $T_{0}=450 \mathrm{~K}$ and $P_{0}=2$ bar.

\subsection{Engine Test Data}

All tests were performed in a single cylinder engine version of the Jaguar Land Rover AJ133 GDI engine [30] at a speed of $1500 \mathrm{rpm}$, an air flow rate of $2 \mathrm{~L} / \mathrm{s}$ and injection at 280 crank angle degrees before top dead centre $\left({ }^{\circ} \mathrm{ca}\right.$ bTDC); this corresponds to a BMEP of about 2 bar. The start of injection was kept fixed to avoid the risk of piston wetting and the possibility of pool fires. Data were logged at high speed $\left(1^{\circ} \mathrm{ca}\right.$ resolution) for approximately 70 cycles at each condition, allowing mean, standard deviation and coefficient of variance $(\mathrm{CoV})$ values to be obtained. Initial tests were performed on each blend and equivalence ratio by sweeping the ignition timing to determine the minimum ignition advance for best torque (MBT). MBT was found by using the spark timing corresponding to highest indicated mean effective pressure (IMEP), and this corresponds to $10 \%$ mass fraction burned (MFB) occurring near top dead centre (TDC) and 50\% MFB occurring at around 
$10^{\circ} \mathrm{ca}$ aTDC. Mass fraction burned (MFB) was determined using the Rassweiler and Withrow method, as explained in many texts, for example [31].

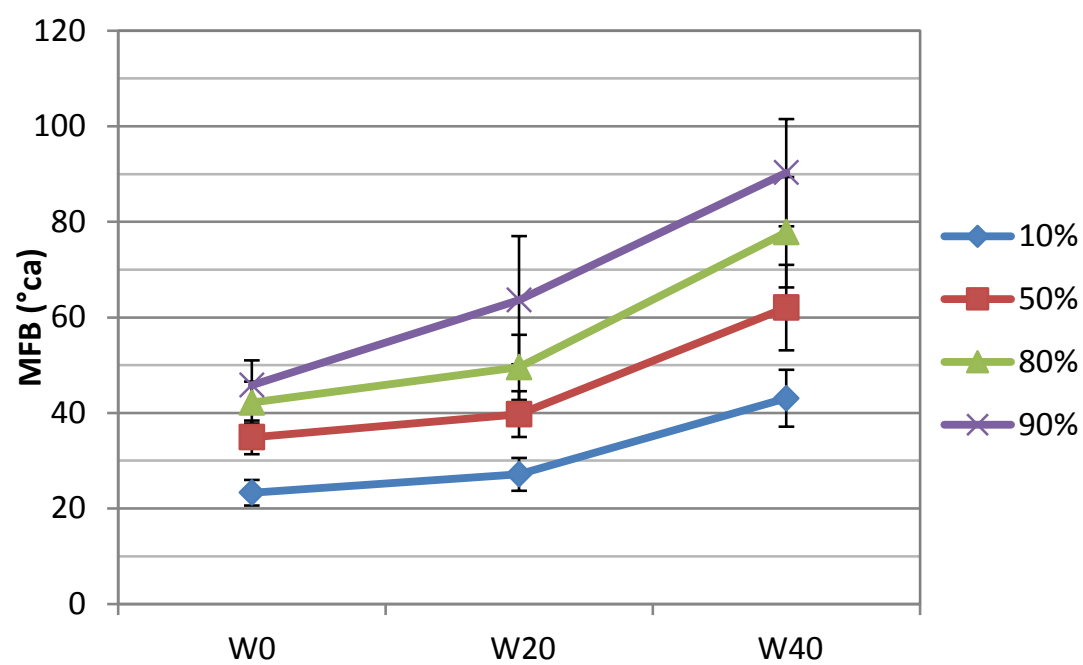

Figure 11 - 10, 50, 80 and 90\% mass fraction burned (MFB) durations for stoichiometric hydrous ethanol blends

The values for 10, 50, 80 and 90\% MFB durations were found for the hydrous ethanol blends for stoichiometric $(\lambda=1.0)$ and rich $(\lambda=0.9)$ mixtures, and are plotted for the stoichiometric data in Figure 11. As expected, slightly faster burn rates were experienced at $\lambda=0.9$ than at $\lambda=1.0$. This is as expected, since for the hydrous ethanol mixtures, determined burning velocities are clearly higher for richer mixtures than for stoichiometric or lean mixtures, with the peak occurring at an equivalence ratio of around $1.1(\lambda \approx 0.9)$.

The clearest trend in Figure 11 is that the increase in water content results in a longer burn duration for all MFB values. The trend here appears to be non-linear by volume, with a bigger increase in burn durations from W20 to W40 than from W0 to W20. The increase in the $0-10 \%$ MFB can be compensated for by advancing the ignition timing $\left(25^{\circ} \mathrm{bTDC}\right.$ for $\mathrm{W} 0,30^{\circ} \mathrm{bTDC}$ for $\mathrm{W} 20$, and $40^{\circ} \mathrm{bTDC}$ for $\left.\mathrm{W} 40\right)$. The increase in the main burn period (10-80\% MFB) duration is from about 
$19^{\circ} \mathrm{ca}$ to $34^{\circ} \mathrm{ca}$, and this is in-line with the changes in the laminar burning velocity. The increase in the main burn period will have an adverse effect on efficiency (of the order of 1 percentage point), [31] but this is minimised as long as the combustion is phased to occur around TDC. The water will lower the combustion temperature and this means there will be less heat transfer, and this mitigates further the impact on efficiency.

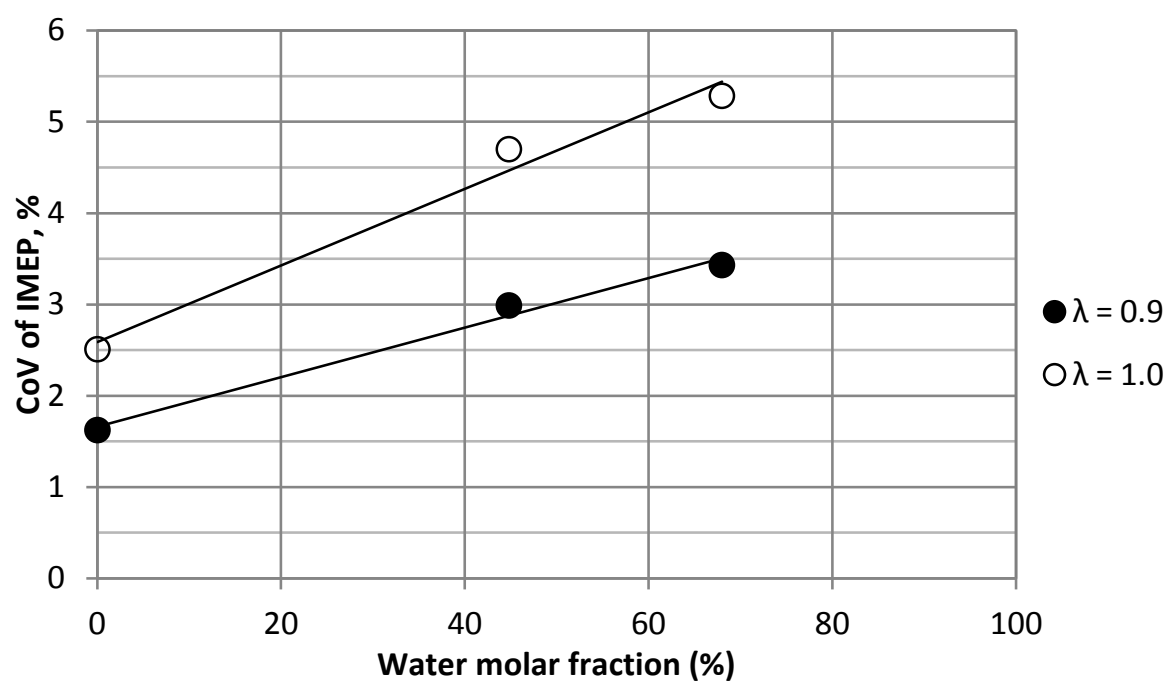

Figure 12 - Coefficient of Variation (CoV) of IMEP for hydrous ethanol mixtures tested at MBT (target BMEP of 2 bar)

The slower combustion will mean that cycle-by-cycle variations increase and Figure 12 shows that the increase is close to linear when plotted against the molar composition, and that the increase is within acceptable levels. 
Burning velocity measurements have been obtained for ethanol mixtures of up to $40 \%$ water by volume, showing how the burning velocity decreases as more water is included. Results from two methods using a combustion bomb have been compared and found to show good agreement and consistency. The development of a correlation (Eq 1 with coefficients listed in Table 3) for burning velocity from the pressure rise data allows estimations to be made for more engine relevant conditions of temperature and pressure (Table 4). The data for pure ethanol is consistent with the limited data in the literature for elevated pressures and temperatures, but there is less suitable data for comparisons of the ethanol-water mixtures. Experimental results derived from schlieren images of the constant pressure phase for hydrous ethanol at 2 bar, $450 \mathrm{~K}$ were found to be in good agreement with the mechanisms of Leplat et al. [25] and the ELTE-EtOH-2016 mechanism of Olm et al. [26].

Also presented are data on the burned gas Markstein length and the pressure at the onset of cellularity (which was found to increase slightly with water content in the ethanol). The Markstein data for ethanol are in broad agreement with the literature, but this is a measurement that is very sensitive to the fitting process. The effect of the equivalence ratio on the Markstein length is in good agreement with previously published data, and the addition of water to the ethanol leads to a slight increase in the Markstein length.

Engine tests have shown that the burn duration increases in-line with the laminar burning velocity, and that the effect of the increased early burn phase should be compensated for by advancing the ignition timing. The slower burn does lead to an increase in the cycle-by-cycle variations in combustion; the coefficient of variation of the IMEP about doubled as the fuel was changed from ethanol to a mixture of ethanol and water that contained $40 \%$ by volume of water. However, this 
441 increase was broadly linear with the mole fraction of water in ethanol, and up to $40 \%$ by volume is 442 within a range that is considered to be acceptable.

\section{Acknowledgements}

\section{References}

1. Directive 2009/28/EC of the European Parliament and of the Council of 23 April 2009 on the promotion of the use of energy from renewable sources and amending and subsequently repealing Directives 2001/77/EC and 2003/30/EC http://eur-lex.europa.eu/legal-content/en/ALL/?uri=CELEX\%3A32009L0028

2. Ormandy, W. R. and Craven, E. C., "Solubility Relations and Other Properties of Mixed Fuels", Report of the Empire Motor Fuels Committee, The Institution of Automobile Engineers vol XVIII Pt I, 1924.

3. Wang, C., Janssen, A., Prakash, A., Cracknell, R. and Xu, H., 2017. Splash blended ethanol in a spark ignition engine-Effect of RON, octane sensitivity and charge cooling. Fuel, 196, pp.21-31.

4. Brewster, S. (2007). "Initial Development of a Turbo-charged Direct Injection E100 Combustion System". 14th Asia Pacific Automotive Engineering Conference. Hollywood, California, USA. SAE.

5. Martinez-Frias, J., S. M. Aceves and D. L. Flowers (2007). "Improving Ethanol Life Cycle Energy Efficiency by Direct Utilization of Wet Ethanol in HCCI Engines." Journal of Energy Resources Technology 129(4): 332. 
6. Edwards, R. Larivé, J-F., Rickeard, D. and Weindorf, W.,"Well-to-Tank: Version 4a-Wellto-Wheels Analysis of Future Automotive Fuels and Powertrains in the European Context, Appendix 2 - Summary of energy and GHG balance of individual pathways" European Commission-Joint Research Centre-Institute for Energy and Transport, Ispra (Italy) (2014). WTT Appendix 2 (Version 4.a) - Summary of energy and GHG balance of individual pathways

7. Edwards, R. Larivé, J-F., Rickeard, D. and Weindorf, W., "Well-to-Tank: Version 4a-Wellto-Wheels Analysis of Future Automotive Fuels and Powertrains in the European Context." European Commission-Joint Research Centre-Institute for Energy and Transport, Ispra (Italy) (2014). WTT Report (Version 4.a)

8. Wang, M., Han, J., Dunn, J.B., Cai, H. and Elgowainy, A., 2012. Well-to-wheels energy use and green-house gas emissions of ethanol from corn, sugarcane and cellulosic biomass for US use. Environmental Research Letters, 7(4), p.045905.

9. Brewster, S., D. Railton, M. Maisey and R. Frew (2007). The Effect of E100 Water Content on High Load Performance of a Spray Guide Direct Injection Boosted Engine. Congresso SAE Brasil. Sao Paulo. 2007-01-2648.

10. Wyman, C. and N. Hinman (1990). "Ethanol: Fundamentals of production from renewable feedstocks and use as a transportation fuel." Applied Biochemistry and Biotechnology 2425(1): 735-753.

11. Costa, R. C. and J. R. Sodré (2010). "Hydrous ethanol vs. gasoline-ethanol blend: Engine performance and emissions." Fuel 89(2): 287-293.

12. Mack, J. H., S. M. Aceves and R. W. Dibble (2009). "Demonstrating direct use of wet ethanol in a homogeneous charge compression ignition (HCCI) engine." Energy 34(6): 782787.

13. Shimada, A. and T. Ishikawa (2013). "Improved thermal efficiency using hydrous ethanol reforming in SI engines." SAE paper 2013-24-0118 
14. Raymond French, Patrick Malone, Phase equilibria of ethanol fuel blends, Fluid Phase Equilibria 228-229 (2005) 27-40

15. Hinton, N., Stone, R and Cracknell, R., 'Laminar burning velocity measurements in constant volume vessels - reconciliation of flame front imaging and pressure rise methods', Fuel $211(2018) 446-457$.

16. Bradley, D., R.A. Hicks, M. Lawes, C.G.W. Sheppard, and R. Woolley, The measurement of laminar burning velocities and Markstein numbers for iso-octane and iso-octane-air mixtures at elevated temperatures and pressures in an explosion bomb. Combustion and Flame, 1998. 115: p. 126-144

17. Lewis, B. and G. Von Elbe, Combustion, Flames and Explosions of Gases, Academic Press Inc. London 1961

18. Konnov, A.A., R.J. Meuwissen, and L.P.H. de Goey, The temperature dependence of the laminar burning velocity of ethanol flames. Proceedings of the Combustion Institute, 2011. 33(1): p. 1011-1019.

19. Gülder, O. L. (1984). "Burning velocities of ethanol-isooctane blends." Combustion and Flame 56(3): 261-268.

20. Bradley, D., M. Lawes and M. S. Mansour (2009). "Explosion bomb measurements of ethanol-air laminar gaseous flame characteristics at pressures up to 1.4MPa." Combustion and Flame 156(7): 1462-1470.

21. Liao, S., D. Jiang, Z. Huang, K. Zeng and Q. Cheng (2007). "Determination of the laminar burning velocities for mixtures of ethanol and air at elevated temperatures." Applied Thermal Engineering 27(2-3): 374-380

22. Eisazadeh-Far, K., A. Moghaddas, F. Rahim and H. Metghalchi (2010). "Burning Speed and Entropy Production Calculation of a Transient Expanding Spherical Laminar Flame Using a Thermodynamic Model." Entropy 12(12): 2485-2496 
23. Zhang, Z., G. Li, L. Ouyang, Z. Pan, F. You and X. Gao (2011). "Experimental determination of laminar burning velocities and Markstein lengths for $75 \%$ hydrous-ethanol, hydrogen and air gaseous mixtures." International Journal of Hydrogen Energy 36(20): 13194-13206.

24. Saxena, P. and F. A. Williams (2007). "Numerical and experimental studies of ethanol flames." Proceedings of the Combustion Institute 31(1): 1149-1156.

25. Leplat, N., P. Dagaut, C. Togbé and J. Vandooren (2011). "Numerical and experimental study of ethanol combustion and oxidation in laminar premixed flames and in jet-stirred reactor." Combustion and Flame 158(4): 705-725.

26. Olm, Carsten, Tamás Varga, Éva Valkó, Sandra Hartl, Christian Hasse, and Tamás Turányi. "Development of an ethanol combustion mechanism based on a hierarchical optimization approach." International Journal of Chemical Kinetics 48, no. 8 (2016): 423-441.

27. Kee, R. J., F. M. Rumpley, and J.A. Miller. “Chemkin-II: A Fortran Chemical Kinetics Package for the Analysis of Gas Phase Chemical Kinetics" Gov. Pub. SAND89-9009B. Sep. 1989.

28. Varea, E., V. Modica, B. Renou and A. M. Boukhalfa (2013). "Pressure effects on laminar burning velocities and Markstein lengths for Isooctane-Ethanol-Air mixtures." Proceedings of the Combustion Institute 34(1): 735-744.

29. Broustail, G., P. Seers, F. Halter, G. Moréac and C. Mounaïm-Rousselle (2011). "Experimental determination of laminar burning velocity for butanol and ethanol iso-octane blends." Fuel 90(1): 1-6.

30. Sandford, Malcolm, Graham Page, and Paul Crawford. The all new AJV8. No. 2009-011060. SAE Technical Paper, 2009.

31. Stone, Richard. Introduction to internal combustion engines. Palgrave Macmillan, 2012. 